\title{
CICLO EVOLUTIVO DO CULEX QUINQUEFASCIATUS (WIEDMANN,1828) (DIPTERA, CULICIDAE) EM CONDIÇÕES DE LABORATÓRIO
}

\author{
Marlene de Fátima Camargo "*, Ionizete Garcia da Silva ${ }^{*}$, Carmeci \\ Natalina Elias ${ }^{* *}$.
}

\section{RESUMO}

A partir de adultos do Culex quinquefasciatus (Wiedmann, 1828) (Diptera,Culicidae), capturados na cidade de Goiânia, coletaram-se ovos e estudou-se o seu desenvolvimento em laboratório, com a finalidade de obter uma criação em grande escala, para testes biológicos com inseticidas, na busca de informaçð̃es que implementem as açð̃es de controle nessa cidade.

O período médio de incubação do C.quinquefasciatus foi de 1,0 dia. As duraç̃̃es médias dos estádios de larva foram de $2.8 ; 1,0 ; 1,8$ e 2,4 dias, respectivamente aos $1^{\circ}, 2^{\circ}, 3^{\circ}$ e $4^{\circ}$ estádios. $O$ estágio de pupa teve duração média de 3,1 dias.Esses deram origem a machos.

As fềmeas tiveram período médio de incubação de 1,0 dia, estádios de larva de 1,$8 ; 1,0 ; 1,8$; e 2,4 dias, respectivamente, ao $1^{\circ}, 2^{\circ}, 3^{\circ}$ e $4^{\circ}$ estádios. $O$ estágio de pupa teve duração média de 2,0 dias.

A duração média do ciclo evolutivo do $C$. quinquefasciatus, para machos e fêmeas, foi, respectivamente de 9 e 10 dias.

Alimentaram-se as fêmeas em camundongos albinos "empastelados", e, os machos, em algodão embebido em mel diluído em água (uma gota de mel por $\mathrm{ml}$ de água).

Os experimentos foram realizados à temperatura de $27 \pm 0,1^{\circ} \mathrm{C}$, umidade relativa de $80 \pm 5 \% \mathrm{e}$ fotoperíodo de 12 horas.

UNITERMOS: Culex quinquefasciatus . Ciclo evolutivo. Culicinae. mosquito.

\section{INTRODUÇÃO}

O C.quinquefasciatus é o mosquito capaz de transmitir a bancroftose (filariose) em áreas de elevada umidade, como por exemplo, a região Norte. Apesar de vasta distribuição e densidade do mosquito, são raros os casos de filariose bancroftiana

- Prof.do Depto. de Parasitologia - IPTSP/UFG - C.P. 131 - Goiânia - Go.

- Técnicos da Fundação Nacional de Saúde - Laboratório de Biologia, Fisiologia de Insetos e Xenodiagnóstico, convênio IPTSP-UFG/FNS

- Recebido para publicação em 14/11/94 
no Brasil, de pouca importância epidemiológica, com baixa prevalência na região amazônica e com resíduos em algumas áreas de Pernambuco (DREYER, 1987; DREYER et al., 1991; DREYER \& BÉLIZ,1988; DREYER \& MEDEIROS, 1990). A maior importância deste mosquito está na irritação e perturbação do sono nos centros urbanos.

Esta espécie é bastante eclética quanto à alimentação sanguínea; suga em qualquer animal sinantrópico, na ausência destes, suga vorazmente o homem. C.quinquefasciatus talvez seja o mosquito melhor adaptado ao meio urbano e se desenvolve em criadouros naturais ou naqueles criados pelo homem, com água, desde a límpida até a extremamente poluída (esgotos). Por isso, é, no momento, a maior praga dos centros urbanos, principalmente naqueles com pouca ou nenhuma infraestrutura de saneamento básico.

Este trabalho teve a finalidade de dominar técnicas de criação em laboratório, esclarecer aspectos da biologia do C.quinquefasciatus para produção de insetos em grande escala e utilizá-los nos testes experimentais com inseticidas, na busca de informações que fomentem as ações de combate ou de controle.

\section{MATERIAL E MÉTODOS}

Origem dos mosquitos - capturaram-se larvas e pupas de C. quinquefasciatus em vários bairros de Goiânia, que foram levadas para o laboratório para completar o ciclo, e, destas, obtiveram-se cerca de 100 adultos, que deram origem à série em estudo.

Câmara biológica - uma câmara foi projetada e construída, tendo em atenção a biologia de C.quinquefasciatus, bem como a segurança para impedir a fuga dos insetos, utilizando uma sala de $3,81 \mathrm{~m}$ de comprimento por $3,24 \mathrm{~m}$ de largura. Nas duas larguras, a parte inferior foi construída de alvenaria (1,0 m de altura) e a outra, uma parede dupa de esquadrias e vidro transparente (semiadiabática). Esta câmara foi climatizada a $27 \pm 0,1^{\circ} \mathrm{C}$, com umidade de $80 \pm 5 \%$, e fotoperíodo natural, cerca de 12 horas.Foran realizadas várias experiências pilotos, com diferentes níveis de umidade, até a obtençio do desenvolvimento do mosquito, de ovo a adulto, sem ocorrer morte do inseto. Este nível de umidade relativa foi de $80 \pm 5 \%$, que foi utilizada na climatização da câmara bológica.

Friscos - para a criação de larvas e pupas foram utilizados frascos de polietileno, zilíndricos e transparentes, medindo $4,0 \mathrm{~cm}$ de diâmetro por $4,7 \mathrm{~cm}$ de altura, aconlicionados dentro de uma bandeja plástica. No estágio de pupa os frascos eram colocalos dentro de uma gaiola, construída por um estrado de madeira, revestido de tela metilica, com cerca de 81 malhas por $\mathrm{cm}^{2}$.O manuseio dos insetos era feito através da itrodução do braço no interior do manguito (similar à manga de camisa) dando acess) ao interior da gaiola.
CAMARGO,M.F.; SILVA,I.G.; ELIAS,C.N. Ciclo Evolutivo do Culex quinquefasciatus (Wiedmann, 1828) (Diptera, Culicidae) em Condiçסes de Laboratório. Rev.Pat.Trop.,23 ( 2 ):191-195, jul./dez.1994,

Alimentação - imediatamente após a eclosão, ofereceu-se alimentação às larvas. Diariamente, colocou-se em cada frasco, ração para peixe, após ter sido triturada no gral com pistilo até se obterem finíssimas partículas. Com o auxílio de um microestilete, com a extremidade úmida, colheu-se uma pequena porção do alimento triturado e este foi colocado sobre a superfície da água do frasco. As fêmeas foram alimentadas em camundongos albinos "empastelados" (SILVA et al.1993b) e, os machos, em algodão (o.b.) embebido em água açucarada (na proporção de $12 \mathrm{~g}$ de açúcar refinado por $250 \mathrm{ml}$ de água).

Incubação - foram separados 100 ovos, imediatamente após a postura, colocados em frascos de $4,0 \times 4,7 \mathrm{~cm}$ com água e acondicionados numa câmara biológica a $27^{\circ} \mathrm{C}$. Os ovos não eclodidos foram observados durante o período que durou o ciclo evolutivo do C.quinquefasciatus.

Larvas, pupas e adultos - após a eclosão, as larvas foram individualizadas em frascos de 4,0 x 4,7 cm, permanecendo nestes até a emergência dos adultos. No estágio de pupa, os frascos eram colocados dentro de uma gaiola (Fig.2) e, posteriormente, procedía-se à determinação do sexo e ao acasalamento.

Das observaçðes diárias, anotaram-se os dados referentes à ecdise das larvas e das pupas, determinadas através das exúvias (cápsula cefálica e epicutícula do tórax e do abdome).

A água usada para o desenvolvimento do C.quinquefasciatus foi da rede pública de abastecimento. Utilizou-se $28 \mathrm{ml}$ de água em cada frasco e a reposição foi feita de acordo com a evaporação, mantendo-se sempre o mesmo nível.

\section{RESULTADOS}

Dos 100 ovos colocados para incubar, eclodiram 93 larvas, num período de 24 horas (um dia), tanto os ovos que deram origem a machos quanto a fêmeas.

A duração média do ciclo evolutivo do C.quinquefasciatus foi de 11,0 dias, para os machos, e, de 10 dias para as fêmeas. Não houve morte durante o desenvolvimento e emergiram 48 machos e 45 fêmeas.

O desenvolvimento do C.quinquefasciatus, de ovo a adulto, foi estatisticamente igual, entre machos e fêmeas. Houve diferença significativa entre os sexos, apenas no primeiro estádio. 
CAMARGO,M.F.; SILVA,I.G.; ELIAS,C.N. Ciclo Evolutivo do Culex quinquefasciatus (Wiedmann, 1828) (Dipter Culicida) em Condiçðes de Laboratório. Rev.Pat Trop. 23 (2):191-195, jul./dez.1994

(1. Dulex quinquefasciatus, à temperatura de

TABELA 1. Duração dos estádios larvais e estágio de pupa de Culex quinquefasciatus, à temperatura de

\begin{tabular}{lll}
\multicolumn{2}{c}{$27^{\circ} \mathrm{C}$ e umidade relativa de $80 \%}$. & Fêmeas \\
\hline Estádios & Machos & $1,8 \pm 0,02$ \\
\hline $1^{\circ}$. & $2,8 \pm 0,06$ & $1,0 \pm 0,04$ \\
$2^{\circ}$ & $1,0 \pm 0,02$ & $1,8 \pm 0,05$ \\
$3^{\circ}$. & $1,8 \pm 0,04$ & $2,4 \pm 0,08$ \\
$4^{\circ}$. & $2,4 \pm 0,07$ & $2,0 \pm 0,04$ \\
Pupa & $2,0 \pm 0,04$ & \\
\hline
\end{tabular}

\section{DISCUSSÃO}

Neste trabalho, desenvolveu-se metodologia de criação do C.quiquefasciatus, para obter produção em alta escala e realizar ensaios biológicos em Goiânia. Os bioensaios são necessários para determinação das dosagens, formulações e eficiência do inseticida.

Com relação ao ciclo evolutivo de mosquitos, existem vários fatores (enzimáticos, por microrganismo, componentes químicos e físicos) que podem estimula- o desenvolvimento ou a diapausa. Neste trabalho, foram observados apenas os estímulos físicos: temperatura, umidade e luminosidade. A temperatura como fator determinante no ritmo do desenvolvimento do C.quinquefasciats foi observado por RUEDA et al.1990. A temperatura e a umidade foram estudades por SILVA et al. $(1993 a$, o) obtiveram o ciclo evolutivo de A.aegypti em 33 dias com uma mortalidade de $25,4 \%$, à temperatura $25^{\circ} \mathrm{C}$ e umidade relativa de $65 \%$. Posteriormente, com temperatura e umidade relativa mais elevadas, $27^{\circ} \mathrm{C}$ e $80 \%$, o ciclo de ovo a adulto foi cerca de 11 dias, sem ocorrer nenhuma mortalidade. Do primeiro para o segundo trabalho houve um aumento de $2^{\circ} \mathrm{C}$ na temperatura e $15 \%$ na umidade relativa. Estas pequenas variações fizeram reduzir em $66,66 \%$ o ciclo evolutivo do A.aegypti.

Nas mesmas condições de laboratório de criar A.aegypti, (SILVA et al., 1993b), estudou-se o desenvolvimento de ovo a adulto do C. quinquefasciatus e verificot-se que o ciclo evolutivo deste culicíneo era estatisticamente igual ao do A.aegypi. Verificou-se também que a umidade de $80 \%$ foi muito favorável ao desenvovimento, visto não ter ocorrido nenhuma morte.Os dados da biologia ajudam a compreender a sazonalidade desta espécie e os períodos de maior densidade, que são de extremaimportância no combate. No laboratório, à temperatura de $27^{\circ} \mathrm{C}$ e umidade de $80 \%$, pude-se obter cerca de três ciclos mensais. Estas condições podem ser considendas similares à estação do verão, e, partes da primavera e do outono, em Goiânia Assim, espera-se para este período, cerca de três gerações mensais e um adensanento de C.quinquefasciatus, aumentando a perturbação e irritação do repouso noturnodos goianiensis.
CAMARGO,M.F.; SILVA,I.G.; ELIAS,C.N. Ciclo Evolutivo do Culex quinquefasciatus (Wiedmann, 1828) (Diptera, Culicidae) em Condiçðes de Laboratório. Rev.Pat Trop.,23 ( 2 ):191-195, jul./dez.1994

\section{SUMMARY}

Evolutive cycle of Culex quinquefasciatus (WIEDMANN, 1828) (Diptera, Culicidae).

The samples of instars larval of Culex quinquefasciatus were collected in Goiânia.The evolutive cycle of C.quinquefasciatus was studied in order to obtain a larger number of mosquitoes reared in laboratory to use in bioassays and to be able to get information for their proper control.

The mean incubation period of C.quinquefasciatus was of 1,0 day. The mean duration of instars larval stage were 2,$8 ; 1,0 ; 1,8$ and 2,4 days, respectively the $1^{\text {st }}, 2^{\text {nd }}$, $3^{\text {rd }}$ and $4^{\text {th }}$ instars, for males, and of 1,$8 ; 1,0 ; 1,8$, and 2,4 ; for females. The mean pupal period was of 2,1 days for males and of 2,0 days for females.

The experiment was performed at $27 \pm 0,1^{\circ} \mathrm{C}, 80 \pm 5 \%$ of relative humidity and photoperiod of 12 hours.

KEYWORDS: Culex quinquefasciatus. Evolutive cycle. Culicinae. Filariose.

\section{REFERÊNCIAS BIBLIOGRÁFICAS}

01. DREYER, G. Filariasis programme - Recife - Brazil.Mem.Inst.Oswaldo Cruz,82(4):359-360, 1987.

02. DREYER, G., ANDRADE, L.; ESPÍRITO SANTO, M.; MEDEIROS, Z.; MOURA, I.; TENÓRIO, J.;

03. DREYER, G. \& BÉLIZ, F.Identificação de microfilária na urina pela técnica de concentração. Rev.Bras.Pat.Clín., 24(4):120-121, 1988.

04. DREYER, G. \& MEDEIROS, Z. Filariose linfática: ainda um desafio.In: Ciência hoje, 12(6):6-7, 1990.

05. RUEDA, L.M.;PATEL, R.C.;AXTELL, R.C. \& STINNER, R.E. Temperature dependent development and survival rates of Culex quinquefasciatus and Aedes aegypti(Diptera: Culicidae).J.Med.Entomol.,27:892-898, 1990.

06. SILVA, I.G.da; CAMARGO, M.F.; ELIAS, M. \& ELIAS, C.N. Ciclo evolutivo de Aedes (Stegomyia) aegypti (Linnaeus, 1762) (Diptera, Culicidae). Rev. Pat. Trop., 22:43-48, 1993a.

07. SILVA, I.G:da; CAMARGO, M.F. \& ELEAS, C.N. Metodologia de criação do Aedes (Stegomyia) aegypti (Linnaeus, 1762) (Diptera, Culicidae).Rev.Goiana Med.,38:1993b, prelo. 
